\title{
A Lower T1 Slope as a Predictor of Subsidence in Anterior Cervical Discectomy and Fusion with Stand-Alone Cages
}

\author{
Su Hun Lee, M.D., 1,2,3 Jun Seok Lee, M.D.,, ${ }^{1,2,3}$ Soon Ki Sung, M.D., Ph.D., ${ }^{1,2,3}$ Dong Wuk Son, M.D., Ph.D., ${ }^{1,2,3}$ \\ Sang Weon Lee, M.D., Ph.D., ${ }^{1,2,3}$ Geun Sung Song, M.D., Ph.D., ${ }^{1,2,3}$ \\ Department of Neurosurgery, Pusan National University Yangsan Hospital, Yangsan, Korea \\ Research Institute for Convergence of Biomedical Science and Technology, ${ }^{2}$ Pusan National University Yangsan Hospital, Yangsan, Korea \\ Department of Neurosurgery, ${ }^{3}$ Pusan National University School of Medicine, Yangsan, Korea
}

Objective : Preoperative parameters including the T1 slope (T1S) and C2-C7 sagittal vertical axis (SVA) have been recognized as predictors of kyphosis after laminoplasty, which is accompanied by posterior neck muscle damage. The importance of preoperative parameters has been under-estimated in anterior cervical discectomy and fusion (ACDF) because there is no posterior neck muscle damage. We aimed to determine whether postoperative subsidence and pseudarthrosis could be predicted according to specific parameters on preoperative plain radiographs.

Methods : We retrospectively analyzed 41 consecutive patients (male : female, 22 : 19; mean age, 51.15 \pm 9.25 years) who underwent ACDF with a stand-alone polyether-ether-ketone (PEEK) cage ( $>1$ year follow-up). Parameters including SVA, T1S, segmental angle and range of motion (ROM), $\mathrm{C} 2-\mathrm{C} 7$ cervical angle and ROM, and segmental inter-spinous distance were measured on preoperative plain radiographs. Risk factors of subsidence and pseudarthrosis were determined using multivariate logistic regression.

Results : Fifty-five segments (27 single-segment and 14 two-segment fusions) were included. The subsidence and pseudarthrosis rates based on the number of segments were $36.4 \%$ and $29.1 \%$, respectively. Demographic data and fusion level were unrelated to subsidence. A greater T1S was associated with a lower risk of subsidence $(p=0.017$, odds ratio $=0.206)$. A cutoff value of T1S $<28^{\circ}$ significantly predicted subsidence (sensitivity : $70 \%$, specificity : $68.6 \%$ ). There were no preoperative predictors of pseudarthrosis except old age.

Conclusion : A lower $\mathrm{T} 1 \mathrm{~S}\left(\mathrm{~T} 1 \mathrm{~S}<28^{\circ}\right)$ could be a risk factor of subsidence following ACDF. Surgeons need to be aware of this risk factor and should consider various supportive procedures to reduce the subsidence rates for such cases.

Key Words : Cervical vertebrae · Postural balance · Spinal fusion · Prosthesis failure · Risk assessment.

\section{INTRODUCTION}

Recently, several studies have been published regarding the preoperative parameters of cervical sagittal balance, including the $\mathrm{C} 2-\mathrm{C} 7$ cervical angle (CA), sagittal vertical axis (SVA), and $\mathrm{T} 1$ slope $(\mathrm{T} 1 \mathrm{~S})^{1,18,30)}$. These parameters are of significance in predicting the changes that occur when the balance between gravity and the force of extension from the posterior

- Received : April 7, 2017 • Revised : May 23, 2017 •Accepted : June 13, 2017

- Address for reprints : Dong Wuk Son, M.D., Ph.D.

Department of Neurosurgery, Pusan National University Yangsan Hospital, 20 Geumo-ro, Mulgeum-eup, Yangsan 50612, Korea Tel : +82-55-360-2126, Fax : +82-55-360-2156, E-mail : md6576@naver.com

This is an Open Access article distributed under the terms of the Creative Commons Attribution Non-Commercial License (http://creativecommons.org/licenses/by-nc/4.0) which permits unrestricted non-commercial use, distribution, and reproduction in any medium, provided the original work is properly cited. 
neck muscle is disturbed. Thus, these factors have been mainly studied in laminoplasty, which severely invades the posterior neck muscular-ligament complex ${ }^{5,15,16,22,26)}$. Because anterior cervical discectomy and fusion (ACDF) does not damage the posterior neck muscular-ligament complex, investigations regarding the influence of preoperative parameters are limited; however, several studies have focused on the preoperative C2C7 CA ${ }^{9,10,12,32)}$. Most recently, Kwon et al. ${ }^{19)}$ approached postACDF cervical alignment using T1S and SVA.

Despite the safety and effectiveness of $\mathrm{ACDF}^{31)}$, the use of a stand-alone cage has been proven to be associated with relatively high subsidence rates and subsequent local kyphosis at the index level ${ }^{7)}$. Various factors including cage type and location, distractive force, and endplate preparation may affect subsidence. In the present study, we considered axial loading as an important factor of subsidence, and focused on axial loading in the neutral cervical position, as this is most frequently imposed on the cage. We assumed that the axial loading differs depending on the cervical alignment. The purpose of the present study was to evaluate the effect of preoperative parameters on postoperative cervical alignment as well as subsidence and pseudarthrosis.

\section{MATERIALS AND METHODS}

\section{Patient population}

Between January 2011 and December 2015, data from 190 patients who underwent ACDF for cervical spondylosis at a single institution were reviewed. The inclusion criteria were as follows : 1) ACDF using a stand-alone polyether-ether-ketone (PEEK) cage and 2) a minimum follow-up period of more than 1 year. Forty-one patients (22 men) met the inclusion and exclusion criteria (Fig. 1). Mean age at surgery was $51.15 \pm 9.25$ years. Twenty-seven patients underwent singlesegment fusion; 14 underwent two-segment fusion. No patients underwent ACDF at more than two levels. In total, 55 disc levels (C3-4, 4; C4-5, 14; C5-6, 25; and C6-7, 12) were investigated. The mean follow-up duration was 16.7 months (range, 12.2-30.3 months). Patients were categorized into subsidence (S group) and non-subsidence groups (non-S group). As another criterion, patients were divided into pseudarthrosis (P group) and fusion groups (non-P group), depending on the presence of pseudarthrosis. Group differ- ences were evaluated for fixed preoperative factors such as age, sex, operative level, diabetes milieus, history of smoking, and body mass index (BMI).

\section{Surgical techniques}

All patients underwent surgery using the standard SmithRobinson anteromedial left-sided approach ${ }^{28)}$. After removal of the intervertebral disc with a careful endplate preparation, a high-speed electric drill and Kerrison punch were used to decompress the nerve roots by removing osteophyte overgrowth on the uncovertebral joint and posterior lips of the vertebral body. We performed bilateral uncinated process resection, even in patients with unilateral symptoms, to eliminate remnant osteophyte regrowth. After the decompression was complete, a stand-alone PEEK cage (CORNERSTONE ${ }^{\circledR}$ PSR; Medtronic Sofamor-Danek, Memphis, TN, USA) was filled with demineralized bone matrix and applied under fluoroscopy. We attempted to position the cage on the anterior edge of the upper vertebra to prevent subsidence. After release of the Caspar distractor, a manual pullout test confirmed the stability of the segments. All patients were instructed to wear a soft collar for 2 months after surgery.

\section{Radiological evaluation}

All radiological assessments were performed at 1-month intervals by an independent observer experienced in spinal diseases. Mean values were calculated and used in the statistical analyses. Lateral standing plain radiographs (neutral standing position facing forward) were performed at the fol-

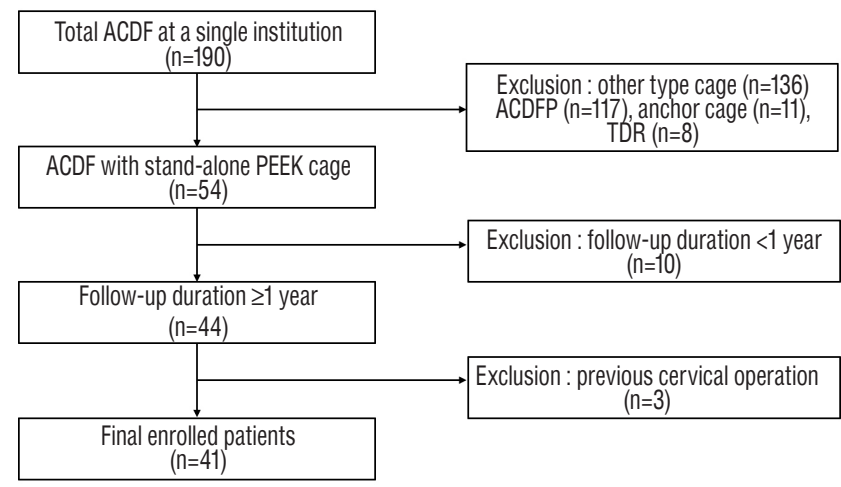

Fig. 1. Flow diagram depicting the patient inclusion process. ACDF : anterior cervical discectomy and fusion, ACDFP : ACDF with anterior plating, TDR : total disc replacement, PEEK : polyether-ether-ketone. 
lowing time points : preoperative (PRE), immediately after surgery, 7 days postoperatively (POST), every 3 months after surgery, and at the latest follow-up examination (F/U). Lateral standing flexion/extension plain radiographs were performed every 3 months starting at 6 months after surgery.

Parameters were measured using commercial software (Marosis 5.0; INFINITT Healthcare, Seoul, Korea) and are summarized in Table 1 . The range of motion (ROM) was defined as the extension angle minus the flexion angle. Alignment of C2-C7 CA $\geq 0$ was defined as lordosis. After the cervical spine compensated for the T1S via cervical lordosis, the additional angle required to restore the cervical sagittal angle to the horizontal line was defined as T1SCA (Fig. 2). The difference between PRE and F/U values for each parameter was designated as the delta $(\Delta)$ value. For example, $\Delta \mathrm{C} 2-\mathrm{C} 7 \mathrm{CA}$ was calculated as F/U C2-C7 CA minus PRE C2-C7 CA. $\Delta$ values were calculated for $\mathrm{C} 2-\mathrm{C} 7 \mathrm{CA}$, segmental angle (SA), and SVA. We defined subsidence as a $\Delta$ total intervertebral height (TIH) $(=$ POST TIH-F/U TIH) $\geq 3 \mathrm{~mm}$. Pseudarthrosis was defined as segmental instability with a $>2 \mathrm{~mm}$ increase in the inter-spinous distance or a segmental ROM $>2^{\circ}$ on the flexion-extension lateral views at most recent follow-up ${ }^{33)}$.

\section{Clinical evaluation}

Clinical evaluations included the neck disability index (NDI), and visual analog scales for neck (VAS-neck) and arm pain (VAS-arm). The evaluations were performed pre- and postoperatively, and at follow-up. At the last follow-up, patients were evaluated according to Odom's criteria, with ratings from excellent to poor $^{24)}$.

\section{Statistical analysis}

The Shapiro-Wilk test was used to confirm normal distribution ( $p>0.05$ ). Group differences ( $\mathrm{S}$ vs. non-S; P vs. non-P) in radiologic and clinical outcomes were evaluated using Student's t-tests and Mann-Whitney $U$ tests for parametric and nonparametric continuous variables, respectively. Pearson's

Table 1. Radiologic parameters and reference of measurement

\begin{tabular}{|c|c|c|c|}
\hline Parameter & Measurement tool & Reference of measurement from/to & Measurement time \\
\hline Lateral standing (Fig. 2A) & & & PRE, POST, F/U \\
\hline $\mathrm{TIH}(\mathrm{mm})$ & Middle line & $\begin{array}{l}\text { UE of cephalic V } \\
\text { LE of caudal V }\end{array}$ & \\
\hline Disc height (mm) & Middle line & $\begin{array}{l}\text { LE of cephalic V } \\
\text { UE of caudal V }\end{array}$ & \\
\hline $\mathrm{C} 2-\mathrm{C} 7 \mathrm{CA}\left({ }^{\circ}\right)$ & Spine Cobb's angle & $\begin{array}{l}\text { LE of } C 2 \mathrm{~V} \\
\mathrm{LE} \text { of } C 7 \mathrm{~V}\end{array}$ & \\
\hline $\mathrm{SA}\left({ }^{\circ}\right)$ & Spine Cobb's angle & $\begin{array}{l}\text { UE of cephalic V } \\
\text { LE of caudal V }\end{array}$ & \\
\hline C2-C7 SVA (mm) & Parallel line & $\begin{array}{l}\text { C2 plumb line posterior margin of } \\
\text { UE of C7 }\end{array}$ & PRE, F/U \\
\hline T1 slope $\left({ }^{\circ}\right)$ & Cobb's angle & $\begin{array}{l}\text { UE of } \mathrm{T1} \\
\text { Horizontal line }\end{array}$ & PRE \\
\hline T1SCA & & T1 slope - C2-C7 CA & \\
\hline Lateral standing dynamic (Fig. 2B, C) & & & PRE, F/U \\
\hline $\mathrm{CA}\left({ }^{\circ}\right)$ & Spine Cobb's angle & Flex CA/Ext CA & \\
\hline $\mathrm{SA}\left({ }^{\circ}\right)$ & Spine Cobb's angle & Flex SA/Ext SA & \\
\hline Inter-spinous distance (mm) & Length & $\begin{array}{l}\text { Spinous process apex of cephalic V } \\
\text { Spinous process apex of caudal V }\end{array}$ & \\
\hline CA ROM $\left({ }^{\circ}\right)$ & & Ext CA- Flex CA & \\
\hline Segmental ROM ( ${ }^{\circ}$ ) & & Ext SA-Flex SA & \\
\hline
\end{tabular}

PRE : pre-operative, POST : post-operative, F/U : follow-up, TIH : total intervertebral height, UE : upper end-plate, $V$ : vertebra body, LE : lower end-plate, CA : cervical angle, SA : segmental angle, SVA : sagittal vertical axis, T1SCA : T1 slope minus C2-7 cervical angle, Flex : flexion, Ext : extension 

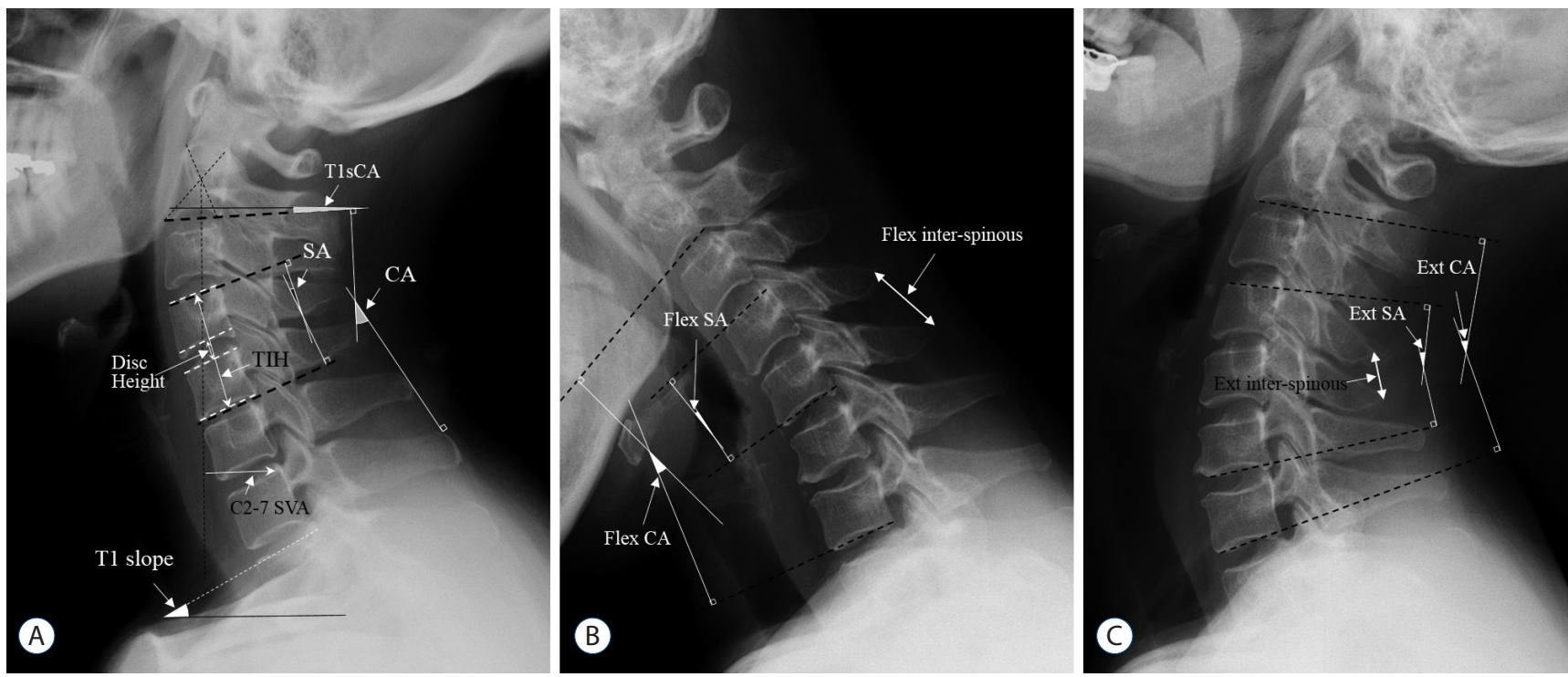

Fig. 2. Measurements of the radiological parameters. $A$ : Neutral lateral image. $B$ : Flexion lateral image, flex : flexion; inter-spinous : inter-spinous distance. C : Extension lateral image. T1SCA : T1S minus CA, SA : segmental angle, CA : C2-C7 cervical angle, TIH : total intervertebral height, SVA : sagittal vertical axis.

Table 2. Patients characteristics and comparative analysis

\begin{tabular}{|c|c|c|c|c|c|c|c|}
\hline & All $(n=41)$ & $\begin{array}{c}\text { Non-subsidence } \\
\text { group }(n=24)\end{array}$ & $\begin{array}{l}\text { Subsidence group } \\
\qquad(n=17)\end{array}$ & $p$-value & $\begin{array}{l}\text { Fusion group } \\
\qquad(n=27)\end{array}$ & $\begin{array}{l}\text { Pseudarthrosis } \\
\text { group }(n=14)\end{array}$ & $p$-value \\
\hline Age (years) & $51.15 \pm 9.25$ & $50.00 \pm 9.19$ & $52.76 \pm 9.35$ & 0.352 & $48.74 \pm 7.63$ & $55.79 \pm 10.56$ & $0.019^{*}$ \\
\hline Sex (male) & $22(53.7)$ & $15(62.5)$ & $7(41.2)$ & 0.177 & $14(51.9)$ & $8(57.1)$ & 0.747 \\
\hline Surgical level & & & & 0.124 & & & 0.754 \\
\hline 1 & 25 & 17 & 8 & & 16 & 9 & \\
\hline 2 & 16 & 7 & 9 & & 11 & 5 & \\
\hline DM & 5 & 2 & 3 & $0.633^{\dagger}$ & 3 & 2 & $>0.999^{\dagger}$ \\
\hline Smoking & 8 & 5 & 3 & $>0.999^{\dagger}$ & 5 & 3 & $>0.999^{\dagger}$ \\
\hline BMI $\left(\mathrm{kg} / \mathrm{m}^{2}\right)$ & $24.53 \pm 2.75$ & $24.90 \pm 3.18$ & $24.01 \pm 1.97$ & 0.315 & $24.34 \pm 2.66$ & $24.90 \pm 3.00$ & 0.542 \\
\hline
\end{tabular}

Values are presented as mean \pm standard deviation or number (\%). ${ }^{*}$ Indicates statistical significance, ${ }^{\dagger}$ Exact Fisher test. DM : diabetes mellitus, BMl : body mass index

correlation analyses were performed, even when only one parameter was normally distributed. Repeated-measure analyses of variance (ANOVAs) were performed to investigate longitudinal trends within T1S groups. A multivariate logistic regression analysis was performed using the backward likelihood ratio (LR) method. A receiver-operating characteristic (ROC) analysis was performed and the cut-off value was defined as the point corresponding to the maximum sum of the sensitivity and specificity. A $p<0.05$ was considered statistically significant. All analyses were performed using SPSS version 21 for Windows (SPSS Inc., Chicago, IL, USA).

\section{RESULTS}

\section{Patient characteristics}

In total, 41 patients ( 55 segments) were included. The rates of subsidence and pseudarthrosis based on the number of segments were $36.4 \%(20 / 55)$ and $29.1 \%$ (16/55), respectively; based on the number of patients, the rates were $41.5 \%$ (17/41) and $34.1 \%$ (14/41), respectively. Table 2 summarizes the patient characteristics and comparative analysis results for the fixed factors. The mean age was significantly higher in the $\mathrm{P}$ group compared to that in the non-P group; other factors did 
not affect subsidence or fusion.

\section{Radiological outcomes}

\section{Preoperative parameters}

The T1S was significantly correlated with $\mathrm{C} 2-\mathrm{C} 7 \mathrm{CA}$ $(\mathrm{r}=0.421, p=0.001)$ and SVA $(\mathrm{r}=0.432, p=0.001)$. SVA was significantly correlated with C2-C7 CA ( $\mathrm{r}=-0.295, p=0.029)$, C2-C7 ROM ( $\mathrm{r}=-0.350, p=0.011)$, and segmental ROM $(\mathrm{r}=-0.558, p<0.001)$. C2-C7 CA was significantly correlated with SA ( $\mathrm{r}=0.447, p=0.001)$. T1SCA was significantly correlated with C2-C7 CA $(\mathrm{r}=-0.768, \mathrm{p}<0.001)$, SA $(\mathrm{r}=-0.355$, $p=0.008)$, SVA $(\mathrm{r}=0.622, p<0.001)$, and PRE SA ROM $(\mathrm{r}=-0.411, p=0.002)$ (Fig. 3).

\section{Postoperative outcomes}

F/U C2-C7 CA, F/U SA, F/U SVA, and F/U T1SCA did not significantly differ from their respective PRE values. However, F/U C2-C7 ROM was significantly decreased compared to the PRE value (Table 3). $\triangle \mathrm{C} 2-\mathrm{C} 7 \mathrm{CA}$ was significantly correlated with PRE C2-C7 CA ( $\mathrm{r}=-0.359, p=0.007)$, PRE SVA $(\mathrm{r}=0.342, p=0.011)$, PRE C2-C7 CA ROM $(\mathrm{r}=-0.291$, $p=0.036)$, PRE T1SCA $(\mathrm{r}=0.326, p=0.015)$, and PRE SA ROM $(\mathrm{r}=-0.363, p=0.008) . \Delta \mathrm{SA}$ was significantly correlated with PRE SA ( $\mathrm{r}=-0.421, p=0.001)$ and PRE SVA $(\mathrm{r}=0.338, p=0.012)$. $\triangle$ SVA was significantly correlated with only PRE SVA $(\mathrm{r}=-0.471, p<0.001)$. The three $\Delta$ values were strongly related to each other $(\Delta \mathrm{C} 2-\mathrm{C} 7 \mathrm{CA}$ and $\triangle \mathrm{SA}: \mathrm{r}=0.505, p \leq 0.001$; $\Delta \mathrm{C} 2-\mathrm{C} 7 \mathrm{CA}$ and $\triangle \mathrm{SVA}: \mathrm{r}=-0.699, p<0.001 ; \Delta \mathrm{SA}$ and $\Delta \mathrm{SVA}$ : $\mathrm{r}=-0.374, p=0.005)$. However, there were no significant relationships between $\Delta$ values and T1S (Table 4).

\section{Subsidence}

Mean $\Delta \mathrm{TIH}$ was $2.33 \pm 1.47 \mathrm{~mm}$ for all segments, $1.43 \pm 0.87$ $\mathrm{mm}$ in the non-S group $(\mathrm{n}=35)$, and $3.90 \pm 0.84 \mathrm{~mm}$ in the $\mathrm{S}$

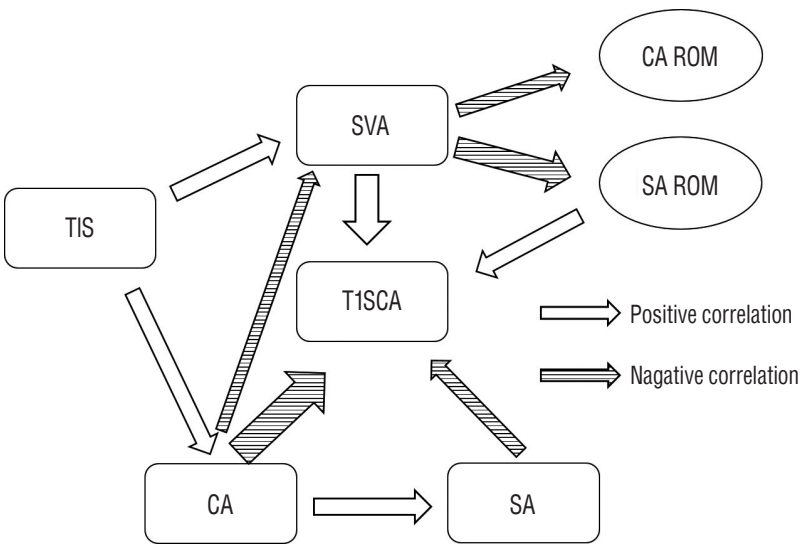

Fig. 3. Correlations among preoperative parameters. The width of the arrow represents the correlation coefficient R. SVA : sagittal vertical axis, T1S : T1 slope, CA : C2-7 cervical angle, ROM : range of motion, SA : segmental angle, T1SCA : T1 slope minus C2-7 cervical angle.

Table 3. The results of radiological parameters and comparative analysis

\begin{tabular}{|c|c|c|c|c|c|c|c|c|c|}
\hline \multirow[b]{2}{*}{ Segment } & \multirow{2}{*}{$\begin{array}{c}\text { PRE } \\
(n=55)\end{array}$} & \multicolumn{3}{|c|}{ Subsidence } & \multicolumn{3}{|c|}{ Pseudarthrosis } & \multicolumn{2}{|c|}{$\mathrm{F} / \mathrm{U}$} \\
\hline & & $\begin{array}{c}\text { Non-S group } \\
(n=35)\end{array}$ & $\begin{array}{l}\text { S group } \\
(n=20)\end{array}$ & $p$-value & $\begin{array}{c}\text { Non-P group } \\
(n=39)\end{array}$ & $\begin{array}{l}\text { P group } \\
(n=16)\end{array}$ & $p$-value & $(n=55)$ & $p$-value \\
\hline T1s & $27.68 \pm 6.95$ & $30.03 \pm 6.02$ & $23.56 \pm 6.65$ & $0.001^{*}$ & $27.30 \pm 6.49$ & $28.59 \pm 8.12$ & 0.538 & - & \\
\hline C2-C7 SVA & $20.75 \pm 12.67$ & $24.17 \pm 12.35$ & $12.78 \pm 11.15$ & $0.007^{*}$ & $20.77 \pm 14.15$ & $20.71 \pm 8.41$ & 0.984 & $21.47 \pm 11.54$ & 0.551 \\
\hline$C 2-C 7 C A$ & $9.65 \pm 10.48$ & $10.92 \pm 10.40$ & $7.42 \pm 10.51$ & 0.237 & $8.38 \pm 10.81$ & $12.74 \pm 9.22$ & 0.164 & $10.32 \pm 10.63$ & 0.534 \\
\hline SA & $0.80 \pm 5.89$ & $0.37 \pm 5.77$ & $1.55 \pm 6.19$ & 0.480 & $0.78 \pm 5.83$ & $0.84 \pm 6.24$ & 0.974 & $0.98 \pm 6.90$ & 0.843 \\
\hline CA ROM & $40.69 \pm 11.77$ & $39.73 \pm 12.41$ & $42.24 \pm 10.78$ & 0.461 & $40.76 \pm 12.95$ & $40.54 \pm 8.89$ & 0.944 & $32.45 \pm 9.05$ & $<0.001^{*}$ \\
\hline SA ROM & $7.60 \pm 4.20$ & $6.66 \pm 4.13$ & $9.11 \pm 3.95$ & $0.039^{\dagger}$ & $7.70 \pm 4.54$ & $7.39 \pm 3.44$ & 0.814 & $2.11 \pm 1.88$ & $<0.001^{*}$ \\
\hline T1SCA & $18.03 \pm 9.84$ & $19.11 \pm 9.64$ & $16.14 \pm 10.14$ & 0.285 & $18.92 \pm 10.17$ & $15.85 \pm 8.90$ & 0.297 & - & \\
\hline Level & & & & $0.326^{\ddagger}$ & & & $0.201^{\ddagger}$ & & \\
\hline C $3-4$ & 4 & 2 & 2 & & 4 & 0 & & & \\
\hline C4-5 & 14 & 7 & 7 & & 12 & 2 & & & \\
\hline C5-6 & 25 & 16 & 9 & & 16 & 9 & & & \\
\hline C6-7 & 12 & 10 & 2 & & 7 & 5 & & & \\
\hline
\end{tabular}

*Indicates $p<0.01,{ }^{\dagger}$ Indicates $p<0.05,{ }^{\ddagger}$ Exact Fisher test. PRE : preoperative, $S$ group : subsidence group, P group : pseudarthrosis group, F/U : follow-up T1s: T1 slope, SVA : sagittal vertical axis, CA : cervical angle, SA : segmental angle, ROM : range of motion, T1SCA : T1 slope minus C2-C7 cervical angle 
group $(n=20)$. Preoperatively, the S group had a lower T1S and SVA, and a higher SA ROM compared to that in the non-S group. Subsidence was significantly correlated with only the T1S ( $\mathrm{r}=-0.351, p=0.009)$. In the linear regression analyses, the relationship between T1S and subsidence was determined as follows : subsidence $=4.381-0.074 \times \mathrm{T} 1 \mathrm{~S}\left(\mathrm{R}^{2}=0.123, p=0.009\right)$. The ROC analysis indicated that a T1S $\geq 28^{\circ}$ could serve as a threshold for a significantly increased risk of subsidence ( $p=0.002$, area under curve $=0.756$, sensitivity $=70 \%$, specificity $=67 \%)$. Using this value, we converted T1S into a bifurcated variable $\left(\mathrm{T} 1 \mathrm{~S}<28^{\circ}, \mathrm{T} 1 \mathrm{~S} \geq 28^{\circ}\right)$ and performed a multivariate logistic regression analysis, which revealed that this threshold value was significantly associated with subsidence $(p=0.017$, odds ratio $=0.206,95 \%$ confidence interval $=0.056-0.757$ ). T1S groups based on this bifurcated variable showed a significant difference in longitudinal trends for TIH, C2-C7 CA, and SA
(Fig. 4).

\section{Pseudarthrosis}

There were no preoperative parameters associated with pseudarthrosis (Table 3 ). According to $\chi^{2}$ test, pseudarthrosis and subsidence were not related to each other $(p=0.911)$.

\section{Clinical outcomes}

All parameters were improved at the last follow-up compared to preoperative values (VAS-neck, PRE : 5.00 $\pm 1.78, \mathrm{~F} / \mathrm{U}$ : $2.73 \pm 1.14, \mathrm{p}<0.001$; VAS-arm, PRE : 6.39 $\pm 1.15, \mathrm{~F} / \mathrm{U}: 2.41 \pm$ $1.11, p<0.001$; NDI, PRE : 44.76 $\pm 1.52, \mathrm{~F} / \mathrm{U}: 18.39 \pm 12.24$, $p<0.001$ ); however, there were no differences in subsidence or pseudarthrosis. Furthermore, Odom's criteria were not significantly different between the $S$ and non-S groups, or between the $\mathrm{P}$ and non-P groups. There were 6 cases of surgery-

Table 4. Correlation analysis between postoperative change and preoperative factors

\begin{tabular}{|c|c|c|c|c|c|c|}
\hline & \multicolumn{6}{|c|}{ Pre-operative parameters } \\
\hline & CA & SA & SVA & T1S & ROM CA & ROM SA \\
\hline \multirow[t]{2}{*}{$\triangle \mathrm{CA}$} & $r=-0.359^{*}$ & $r=-0.173$ & $r=0.342^{*}$ & $r=-0.080$ & $r=-0.291^{\dagger}$ & $r=-0.363^{*}$ \\
\hline & $p=0.007$ & $p=0.206$ & $p=0.011$ & $p=0.560$ & $p=0.036$ & $p=0.008$ \\
\hline \multirow[t]{2}{*}{$\triangle S A$} & -0.082 & $-0.421^{*}$ & $0.338^{\dagger}$ & 0.225 & -0.259 & -0.269 \\
\hline & 0.554 & 0.001 & 0.012 & 0.098 & 0.064 & 0.054 \\
\hline \multirow[t]{2}{*}{$\triangle S V A$} & 0.151 & 0.107 & $-0.472^{*}$ & -0.086 & 0.247 & $0.308^{\dagger}$ \\
\hline & 0.271 & 0.436 & $<0.001$ & 0.532 & 0.078 & 0.026 \\
\hline \multirow[t]{2}{*}{$\triangle \mathrm{TIH}$} & -0.200 & -0.023 & -0.238 & $-0.351^{*}$ & 0.078 & 0.239 \\
\hline & 0.142 & 0.868 & 0.080 & 0.009 & 0.581 & 0.088 \\
\hline
\end{tabular}

*Indicates $p<0.01,{ }^{\dagger}$ Indicates $p<0.05$. CA : C2_C7 cervical angle, SA : segmental angle, SVA : sagittal vertical axis, T1S : T1 slope, ROM : range of motion; $\Delta$ : the value of last follow-up minus the value of pre-operative value, $\mathrm{TIH}$ : total intervertebral height

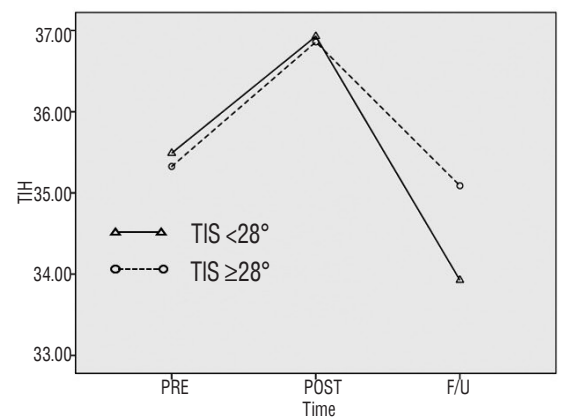

(A)

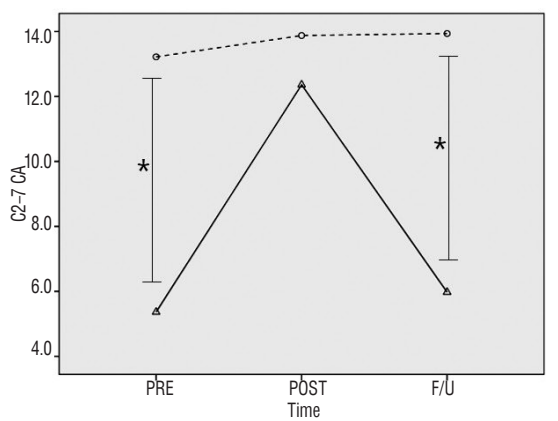

(B)

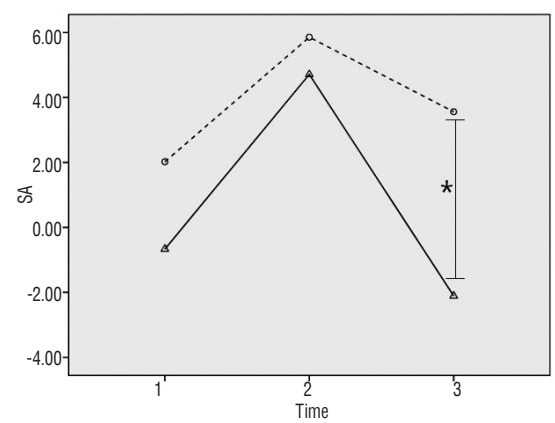

(C)
$S A^{\dagger}$

Fig. 4. Effect of $\mathrm{T} 1$ slope on cervical alignment. ${ }^{*}$ Significant group difference at each time point $(p<0.05)$, ${ }^{\dagger}$ Significant group difference in the longitudinal trend $(p<0.05)$. TIH : total intervertebral height, T1S:T1 slope, CA : C2-7 cervical angle, SA : segmental angle. 


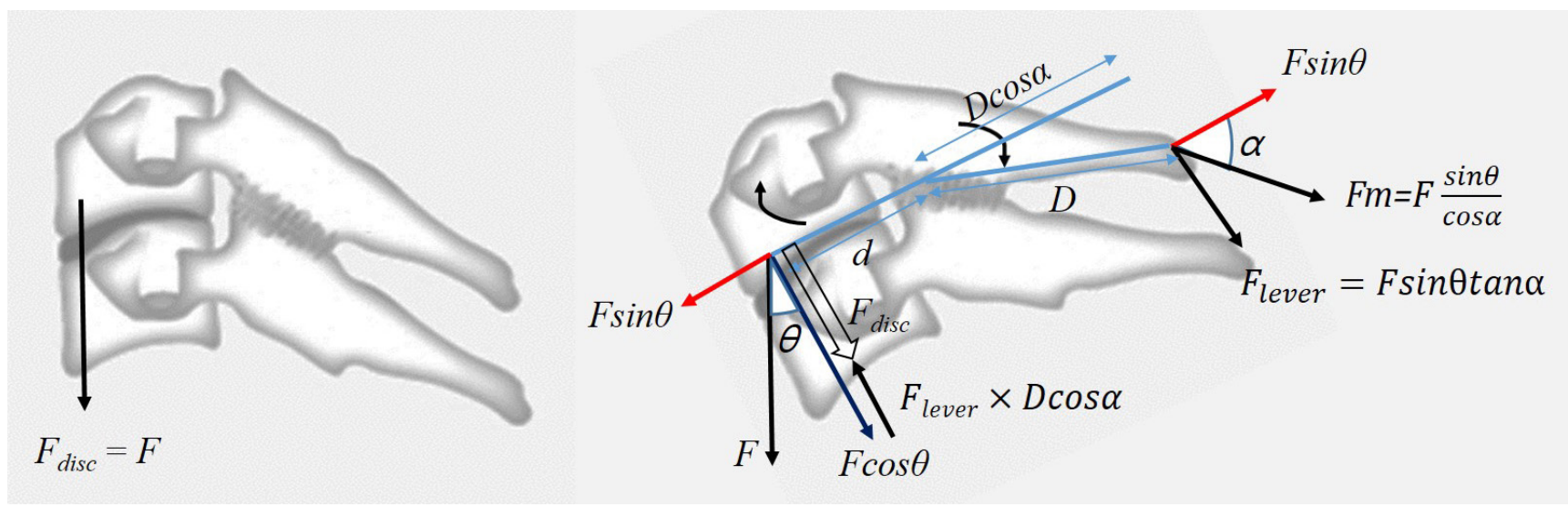

Fig. 5. Scheme illustrating the statistical analysis. $F:$ force, $\theta: T 1$ slope, $a$ : the angle between spinous process and $F \sin \theta$, $F_{\text {disc }}:$ loading on disc.

related complications as follows : transient recurrent laryngeal nerve palsy $(\mathrm{n}=2)$, C5 nerve palsy $(\mathrm{n}=1)$, superficial surgical site infection $(n=1)$, transient clinical dysphagia $(n=1)$, and cephalic vertebral body fracture $(n=1)$. There were two cases in which the patients had poor Odom's criteria, one patient had an intractable hand tremor with an unknown cause, and one patient reported severe axial pain that was worse compared to that before surgery (PRE VAS-neck : 3, F/U VAS-neck : 6).

\section{DISCUSSION}

Cervical alignment has a significant effect on postoperative clinical outcomes ${ }^{11,14)}$. In particular, studies on kyphosis after laminoplasty or long-level posterior fusion with accompanying injuries in the posterior neck muscles are currently in progress $^{5,13,16,29)}$. However, to our knowledge, only one study has investigated the effect of ACDF on cervical sagittal parameters $^{19)}$.

The reported factors affecting cervical alignment after ACDF include preoperative alignment ${ }^{2,20)}$, intra-operative segmental distraction ${ }^{6}$, surgical level (single or multiple) ${ }^{9)}$, and cage characteristics ${ }^{3,8,27)}$. In addition, postoperative subsidence causes unexpected changes in cervical alignment. Pseudarthrosis indicates that the cervical alignment changes can proceed further ${ }^{17)}$. In addition to these factors, age, BMI, smoking history, low bone mineral density ${ }^{4}$, endplate preparation $^{21)}$, and cage size and location ${ }^{25)}$ are known risk factors for subsidence. However, few studies exist regarding factors such as preoperative T1S and SVA.
The conclusions drawn in previous studies regarding T1S and SVA can be summarized as follows : T1S is an individual intrinsic value ${ }^{5)}$ determined by the thoracolumbar alignment ${ }^{1}$, and compensated by cervical lordosis and SVA change. However, after surgeries, such as laminoplasty, with accompanying posterior neck muscle injury, this compensation becomes insufficient, resulting in kyphosis. In the present study, we observed changes in preoperative parameters that were similar to those of the previous study ${ }^{19)}$. In addition, as SVA increases, the CA ROM and SA ROM decrease. It is considered that motion is additionally reduced because the posterior neck muscle extension is already being used to maintain alignment.

Nolan and Sherk ${ }^{23)}$ reported that the semispinalis cervicis and capitis muscles, the interspinous and supraspinous ligaments, which constitute the cervical spinous process ligament-muscle complex (SPLMC), are important factors in maintaining cervical sagittal dynamic and static balance. From a statistical point of view (Fig. 5), as the T1S increases, the cervical spine tends to fall forward $(\mathrm{F} \times \sin \theta)$. To maintain cervical spinal balance, the SPLMC generates force (Fm) to counteract $\mathrm{F} \times \sin \theta$. However, because Fm acts on the spinous process axis, $\mathrm{F} \times \sin \theta$ does not coincide with the axis. Therefore, while part of Fm is used to counteract F $\times \sin \theta$, the rest of the force acts on a type of lever. This lever consists of the fulcrum (facet), effort side (spinous process), and load side (vertebral body). The force acting on the spinous process is converted to the opposite direction on the loading side, and this force $\left(\mathrm{F}_{\text {lever }}\right)$ is thought to reduce the loading on the cage. Furthermore, in the linear regression analysis of subsidence 
and T1S, conversion of T1S to cos shows a much higher significance $\left(\mathrm{R}^{2}=0.737, p<0.001\right)$ compared to that for the angle alone $\left(\mathrm{R}^{2}=0.123, p=0.009\right)$. In addition, the tendency of CA to increase as T1S increases is also explained by this force $\left(\mathrm{F}_{\text {lever }}\right)$, which induces lordosis by extending each segment. After laminoplasty, the ability to counteract $\mathrm{F} \times \sin \theta$ is decreased because of the fibrotic change in the SPLMC. When laminoplasty is performed in patients with a large T1S, SPLMC cannot counter $\mathrm{F} \times \sin \theta$, resulting in SVA increases. However the insufficiency of the counteracting $\mathrm{F} \times \sin \theta$ cannot explain kyphosis. We hypothesized that a decrease in $\mathrm{F}_{\text {lever, }}$ which acts to extend each segment, is the cause of kyphosis.

Pseudarthrosis was not affected by any preoperative factors in the present study; however it was affected by age. In addition, there was no association with subsidence in the non-S group $(10 / 35[28.6 \%])$ or in the $\mathrm{S}$ group $(6 / 20$ [30.0\%]). However, the pseudarthrosis incidence rates were 5/25 (20\%) in the $\mathrm{T} 1 \mathrm{~S}<28^{\circ}$ group and $11 / 30(36.7 \%)$ in the $\mathrm{T} 1 \mathrm{~S} \geq 28^{\circ}$ group. These results, although not statistically significant, suggest that further evaluation in larger-scale studies is needed.

This study had several limitations. We analyzed only ACDF with a stand-alone cage; cases with an anterior plate or anchoring cage were excluded due to differences in the static mechanism features. Second, the present study included twosegment ACDF and was not limited to a single level (e.g., only C5-6). Even with this limitation, we obtained high statistical significance. Nevertheless, for a more accurate mechanical analysis, one-segment single-level ACDF studies are required. Third, the static analysis was limited to the force acting on the sagittal plane of the cervical vertebrae, and did not include various actual forces; future cadavaric and fine element analysis studies are required. Finally, the study was smallsized and had a relatively short-term follow-up; differences in clinical outcomes according to fusion or subsidence could not be determined. The impact of subsidence on these factors is still controversial; however, a recent report suggests that sub subsidence is associated with poor long-term clinical outcomes $^{17)}$. Thus, minimizing subsidence is of importance and future large-scale, long-term studies are needed.

The present results have significant clinical implications. First, efforts to reduce subsidence in patients with low T1S should be taken. Although this study did not demonstrate a clinical difference, a recent long-term study noted that subsidence groups reported worse long-term outcomes and mal- alignment ${ }^{17)}$. To reduce subsidence, a plate that disperses the loading on the cage may be applied; a more careful endplate preparation or lower-elasticity graft such as an allograft application may also be considered. Second, the effect of indirect decompression by the cage insertion will be decreased due to high degrees of subsidence. Thus, we should consider sufficient direct decompression to prevent symptom recurrence according to subsidence in low TIS patients.

\section{CONCLUSION}

Lower T1 sagittal slope could be a risk factor of subsidence following ACDF. According to the ROC curve analysis, a preoperative T1 sagittal slope $<28^{\circ}$ is likely to predict the development of subsidence. Surgeons need to be aware of this risk factor, which can be detected on preoperative plain radiographs, and should consider various supportive procedures to reduce the subsidence rate in such cases.

\section{- Acknowledgements}

This study was supported by a 2017 research grant from Pusan National University Yangsan Hospital.

All procedures performed in studies involving human participants were in accordance with the ethical standards of Institutional Review Board (IRB) of the hospital (IRB No. : 052017-036) and with the 1964 Helsinki declaration and its later amendments or comparable ethical standards. The study protocol was approved by the IRB of Pusan National University Yangsan Hospital, which waived the requirement for informed consent due to the retrospective nature of this study.

\section{References}

1. Ames CP, Blondel B, Scheer JK, Schwab FJ, Le Huec JC, Massicotte EM, et al. : Cervical radiographical alignment: comprehensive assessment techniques and potential importance in cervical myelopathy. Spine (Phila Pa 1976) 38(22 Suppl 1) : S149-S160, 2013

2. Barsa P, Suchomel $P$ : Factors affecting sagittal malalignment due to cage subsidence in standalone cage assisted anterior cervical fusion. Eur Spine J 16 : 1395-1400, 2007

3. Bartels RH, Donk RD, Feuth $T$ : Subsidence of stand-alone cervical carbon fiber cages. Neurosurgery 58 : 502-508; discussion 502 508, 2006 
4. Brenke C, Dostal M, Scharf J, Weiss C, Schmieder K, Barth M : Influence of cervical bone mineral density on cage subsidence in patients following stand-alone anterior cervical discectomy and fusion. Eur Spine J 24 : 2832-2840, 2015

5. Cho JH, Ha JK, Kim DG, Song KY, Kim YT, Hwang CJ, et al. : Does preoperative T1 slope affect radiological and functional outcomes after cervical laminoplasty? Spine (Phila Pa 1976) 39 : E1575-E1581, 2014

6. Francke El, Demetropoulos CK, Agabegi SS, Truumees E, Herkowitz HN : Distractive force relative to initial graft compression in an in vivo anterior cervical discectomy and fusion model. Spine (Phila Pa 1976) 35 : 526-530, 2010

7. Fujibayashi $\mathrm{S}, \mathrm{Neo} M$, Nakamura $\mathrm{T}$ : Stand-alone interbody cage versus anterior cervical plate for treatment of cervical disc herniation: sequential changes in cage subsidence. J Clin Neurosci 15 : 1017-1022, 2008

8. Gercek E, Arlet V, Delisle J, Marchesi D : Subsidence of stand-alone cervical cages in anterior interbody fusion: warning. Eur Spine J 12 : 513516, 2003

9. Gillis CC, Kaszuba MC, Traynelis VC : Cervical radiographic parameters in 1- and 2-level anterior cervical discectomy and fusion. J Neurosurg Spine 25 : 421-429, 2016

10. Gum JL, Glassman SD, Douglas LR, Carreon LY : Correlation between cervical spine sagittal alignment and clinical outcome after anterior cervical discectomy and fusion. Am J Orthop (Belle Mead NJ) 41 : E81E84, 2012

11. Harrison DD, Troyanovich SJ, Harrison DE, Janik TJ, Murphy DJ : A normal sagittal spinal configuration: a desirable clinical outcome. J Manipulative Physiol Ther 19 : 398-405, 1996

12. Huang DN, Yu M, Xu NF, Li M, Wang SB, Sun Y, et al. : The relationship between changes of cervical sagittal alignment after anterior cervical discectomy and fusion and spino-pelvic sagittal alignment under roussouly classification: a four-year follow-up study. BMC Musculoskelet Disord $18: 87,2017$

13. Hyun SJ, Kim KJ, Jahng TA, Kim HJ : Relationship between T1 slope and cervical alignment following multilevel posterior cervical fusion surgery: impact of T1 slope minus cervical lordosis. Spine (Phila Pa 1976) 41 : E396-E402, 2016

14. Kawakami M, Tamaki T, Yoshida M, Hayashi N, Ando M, Yamada H : Axial symptoms and cervical alignments after cervical anterior spinal fusion for patients with cervical myelopathy. J Spinal Disord 12 : 50-56, 1999

15. Kim B, Yoon DH, Ha Y, Yi S, Shin DA, Lee CK, et al. : Relationship between $\mathrm{T} 1$ slope and loss of lordosis after laminoplasty in patients with cervical ossification of the posterior longitudinal ligament. Spine J 16 : 219-225, 2016

16. Kim TH, Lee SY, Kim YC, Park MS, Kim SW : T1 slope as a predictor of kyphotic alignment change after laminoplasty in patients with cervical myelopathy. Spine (Phila Pa 1976) 38 : E992-E997, 2013

17. Kim WB, Hyun SJ, Choi H, Kim KJ, Jahng TA, Kim HJ : Long-term followup results of anterior cervical inter-body fusion with stand-alone cages. J Korean Neurosurg Soc 59 : 385-391, 2016

18. Knott PT, Mardjetko SM, Techy F : The use of the $\mathrm{T} 1$ sagittal angle in predicting overall sagittal balance of the spine. Spine J $10: 994-998$, 2010

19. Kwon WK, Kim PS, Ahn SY, Song JY, Kim JH, Park YK, et al. : Analysis of associating factors with C2-7 sagittal vertical axis after two-level anterior cervical fusion: comparison between plate augmentation and standalone cages. Spine (Phila Pa 1976) 42 : 318-325, 2017

20. Lee YS, Kim YB, Park SW : Risk factors for postoperative subsidence of single-level anterior cervical discectomy and fusion: the significance of the preoperative cervical alignment. Spine (Phila Pa 1976) 39 : 12801287, 2014

21. Lim $T H$, Kwon $H$, Jeon $C H$, Kim JG, Sokolowski M, Natarajan R, et al. : Effect of endplate conditions and bone mineral density on the compressive strength of the graft-endplate interface in anterior cervical spine fusion. Spine (Phila Pa 1976) 26 : 951-956, 2001

22. Lin S, Zhou F, Sun Y, Chen Z, Zhang F, Pan S: The severity of operative invasion to the posterior muscular-ligament complex influences cervical sagittal balance after open-door laminoplasty. Eur Spine J 24 : 127 135, 2015

23. Nolan JP Jr, Sherk HH : Biomechanical evaluation of the extensor musculature of the cervical spine. Spine (Phila Pa 1976) 13 : 9-11, 1988

24. Odom GL, Finney W, Woodhall B : Cervical disk lesions. J Am Med Assoc $166: 23-28,1958$

25. Park JY, Choi KY, Moon BJ, Hur H, Jang JW, Lee JK : Subsidence after single-level anterior cervical fusion with a stand-alone cage. J Clin Neurosci $33: 83-88,2016$

26. Sakai K, Yoshii T, Hirai T, Arai Y, Torigoe I, Tomori M, et al. : Cervical sagittal imbalance is a predictor of kyphotic deformity after laminoplasty in cervical spondylotic myelopathy patients without preoperative kyphotic alignment. Spine (Phila Pa 1976) 41 : 299-305, 2016

27. Schmieder K, Wolzik-Grossmann M, Pechlivanis I, Engelhardt M, Scholz $M$, Harders $A$ : Subsidence of the wing titanium cage after anterior cervical interbody fusion: 2-year follow-up study. J Neurosurg Spine 4 : 447-453, 2006

28. Smith GW, Robinson RA : The treatment of certain cervical-spine disorders by anterior removal of the intervertebral disc and interbody fusion. J Bone Joint Surg Am 40-A : 607-624, 1958

29. Tang JA, Scheer JK, Smith JS, Deviren V, Bess S, Hart RA, et al. : The impact of standing regional cervical sagittal alignment on outcomes in posterior cervical fusion surgery. Neurosurgery 76 Suppl 1 : S14-S21; discussion S21, 2015

30. Tang JA, Scheer JK, Smith JS, Deviren V, Bess S, Hart RA, et al. : The impact of standing regional cervical sagittal alignment on outcomes in posterior cervical fusion surgery. Neurosurgery 71 : 662-669; discussion 669, 2012

31. Thomé C, Leheta $\mathrm{O}$, Krauss JK, Zevgaridis D : A prospective randomized comparison of rectangular titanium cage fusion and iliac crest autograft fusion in patients undergoing anterior cervical discectomy. J Neurosurg Spine $4:$ 1-9, 2006

32. Tomé-Bermejo F, Morales-Valencia JA, Moreno-Pérez J, Marfil-Pérez J, Díaz-Dominguez E, Piñera AR, et al. : Long-term changes in sagittal alignment and its clinical implications after cervical interbody fusion 
J Korean Neurosurg Soc 60 | September 2017

cage subsidence for degenerative cervical disc disease. A prospective study with standalone lordotic tantalum cages. Clin Spine Surg, 2016 [Epub ahead of print]
33. Yang JJ, Yu CH, Chang BS, Yeom JS, Lee JH, Lee CK : Subsidence and nonunion after anterior cervical interbody fusion using a stand-alone polyetheretherketone (PEEK) cage. Clin Orthop Surg 3 : 16-23, 2011 